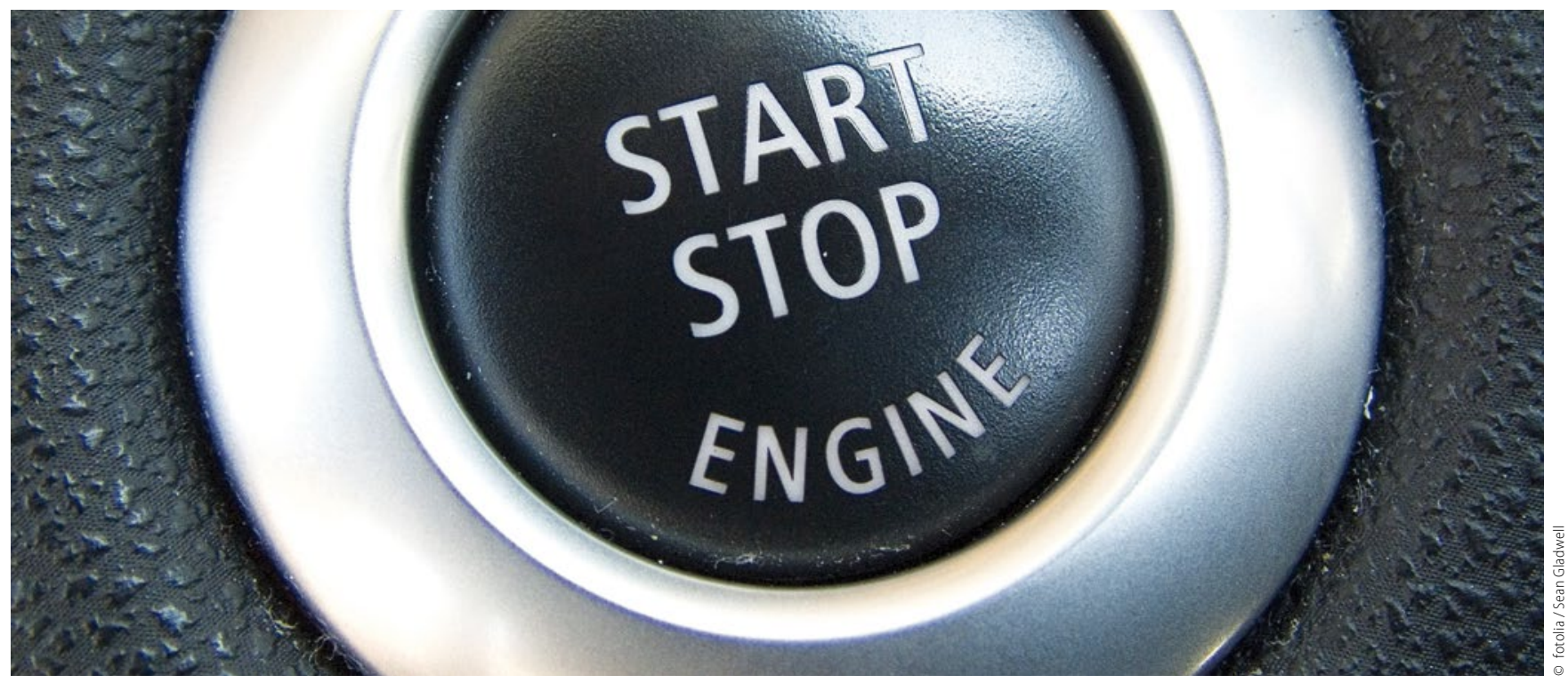

Fehlerhaftes Leistungsverzeichnis

\title{
Vorstand der Bundesärztekammer stoppt GOÄ-Novelle
}

Die Verhandlungen über eine neue Gebührenordnung für Ärzte (GOÄ) haben Mitte März ein jähes Ende genommen. Völlig überraschend hat der Vorstand der Bundesärztekammer (BÄK) dem 700 Seiten langen, praktisch fertigen GOÄ-Konzept die Zustimmung verweigert. Die offizielle Begründung: Unstimmigkeiten bei den Leistungslegenden.

Eigentlich sollte es eine reine Formalie sein. Als sich der BÄKVorstand am 19. März in Berlin traf, war zu erwarten, dass das Präsidium die fertige GOÄ-Vorlage absegnet, bevor sie dem Bundesgesundheitsministerium übergeben werden sollte. Doch dann lehnte das Gremium den Entwurf einer Gebührenordnung für privatärztliche Leistungen vorerst ab. Die Entscheidung fiel einstimmig. Seitens der BÄK hieß es, dass der „Vorstand der Bundesärztekammer den aktuellen Diskussionsstand zum Leistungsverzeichnis der GOÄneu eingehend erörtert und weiteren Diskussionsbedarf festgestellt hat". Als erste Reaktion auf das Ergebnis trat Dr. Theodor Windhorst mit sofortiger Wirkung als Verhandlungsführer der BÄK und Chef des GOÄ-Ausschusses zurück.

Somit gipfelten die langen und äußerst umstrittenen Verhandlungen um eine neue Gebührenordnung in einem Eklat. Für die Außenwelt vor allem überraschend war das Verhalten des BÄK-Vorstandes. Denn erst Ende Januar hatte bei einem außerordentlichen Ärztetag die große Mehrheit der 250 Delegierten den Verhandlungsführern den Rücken gestärkt und ein „Weiter so!“ gefordert. Den außerordentlichen Ärztetag hatten die Delegiertenversammlungen der Landesärztekammer BadenWürttemberg sowie der Brandenburgischen Ärztekammer und der Ärztekammer Berlin (siehe auch Interview Seite 31) beantragt. Die Hauptkritikpunkte bei den GOÄ-Verhandlungen lau- teten: Intransparenz, inakzeptable Kompromisse und zu viele Fehler im vorlegten Leistungsverzeichnis. Die Kritiker befürchten vor allem den Verlust der freiberuflichen Grundpfeiler sowie eine „EBMisierung der GÖ̈“.

\section{Heftige Kritik vom Präsidenten}

Durch den Verhandlungsstopp rückt das ursprüngliche Ziel, die GOÄ-Reform noch in dieser Legislaturperiode zu verabschieden, in weite Ferne. Auch BÄK-Präsident Professor Frank-Ulrich Montgomery gab gegenüber der Frankfurter Allgemeinen Zeitung (FAZ) zu, dass das bis zur nächsten Bundestagswahl 2017 wohl nicht mehr klappe. Als einen Grund nannte Montgomery den anhaltenden innerärztlichen Widerstand und kritisierte die Gegner heftig: „Das Problem ist, dass einzelne Verbände oder auch nur einzelne Personen mit großer Intensität die Modernisierung bekämpfen. Vermutlich wollen manche im Grunde lediglich die alte GOÄ erhalten“, zitierte die FAZ den Ärztepräsidenten.

Eine Welle von Kritik könnte Montgomery selbst beim nächsten Ärztetag Ende Mai entgegenschlagen. Aus den Reihen der Ärzteschaft ist zu hören, dass der Präsident endlich Verantwortung übernehmen und zurücktreten solle. Und falls er dies ablehne, würde aus der Versammlung heraus ein entsprechender Abwahl-Antrag gestellt, heißt es. 